
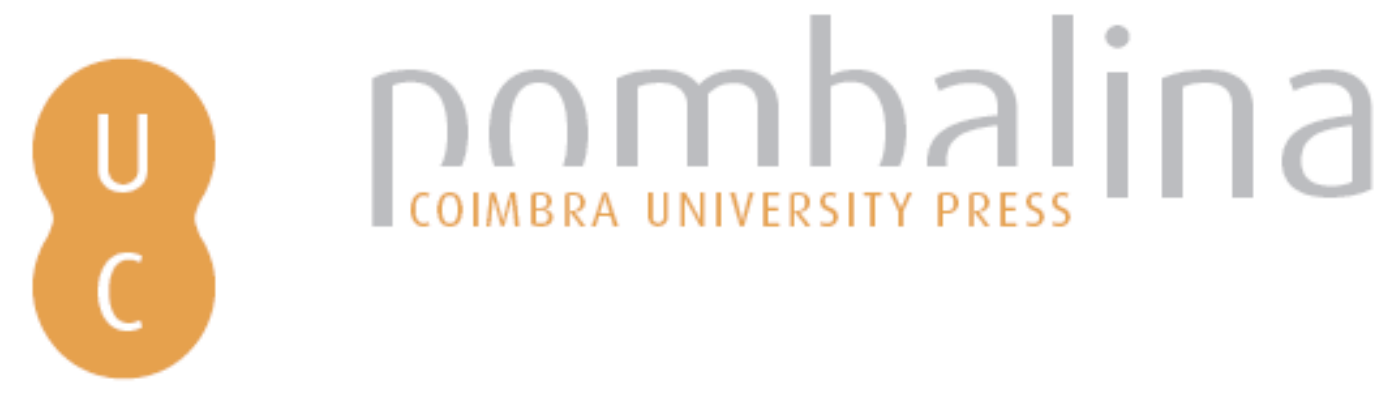

\title{
César e Catilina: personas clássicas do «eu» numa autobiografia americana do século xx - o caso de Memories of a Catholic Girlhood, de Mary McCarthy
}

\author{
Autor(es): $\quad$ Pedro, Isabel \\ Publicado por: Imprensa da Universidade de Coimbra \\ URL \\ persistente: URI:http://hdl.handle.net/10316.2/32115 \\ DOI: $\quad$ DOI:http://dx.doi.org/10.14195/978-989-26-0368-1_6 \\ Accessed : $\quad$ 26-Apr-2023 11:52:47
}

A navegação consulta e descarregamento dos títulos inseridos nas Bibliotecas Digitais UC Digitalis, UC Pombalina e UC Impactum, pressupõem a aceitação plena e sem reservas dos Termos e Condições de Uso destas Bibliotecas Digitais, disponíveis em https://digitalis.uc.pt/pt-pt/termos.

Conforme exposto nos referidos Termos e Condições de Uso, o descarregamento de títulos de acesso restrito requer uma licença válida de autorização devendo o utilizador aceder ao(s) documento(s) a partir de um endereço de IP da instituição detentora da supramencionada licença.

Ao utilizador é apenas permitido o descarregamento para uso pessoal, pelo que o emprego do(s) título(s) descarregado(s) para outro fim, designadamente comercial, carece de autorização do respetivo autor ou editor da obra.

Na medida em que todas as obras da UC Digitalis se encontram protegidas pelo Código do Direito de Autor e Direitos Conexos e demais legislação aplicável, toda a cópia, parcial ou total, deste documento, nos casos em que é legalmente admitida, deverá conter ou fazer-se acompanhar por este aviso.

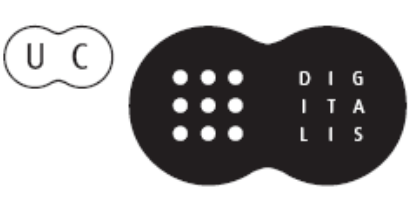


Carmen Soares

Inês Calero Secall

Maria do Céu Fialho

Coordenação

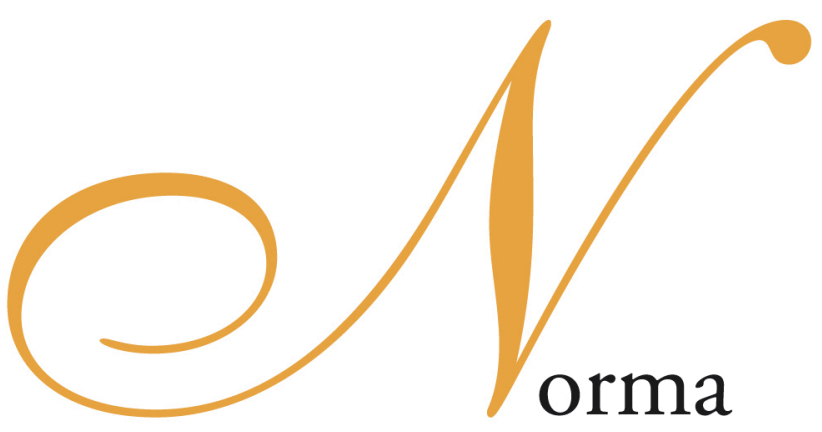

\& Transgressão 
(Página deixada propositadamente em branco) 


\author{
Carmen Soares \\ Inés Calero Secall \\ Maria do Céu Fialho \\ Coordenação
}
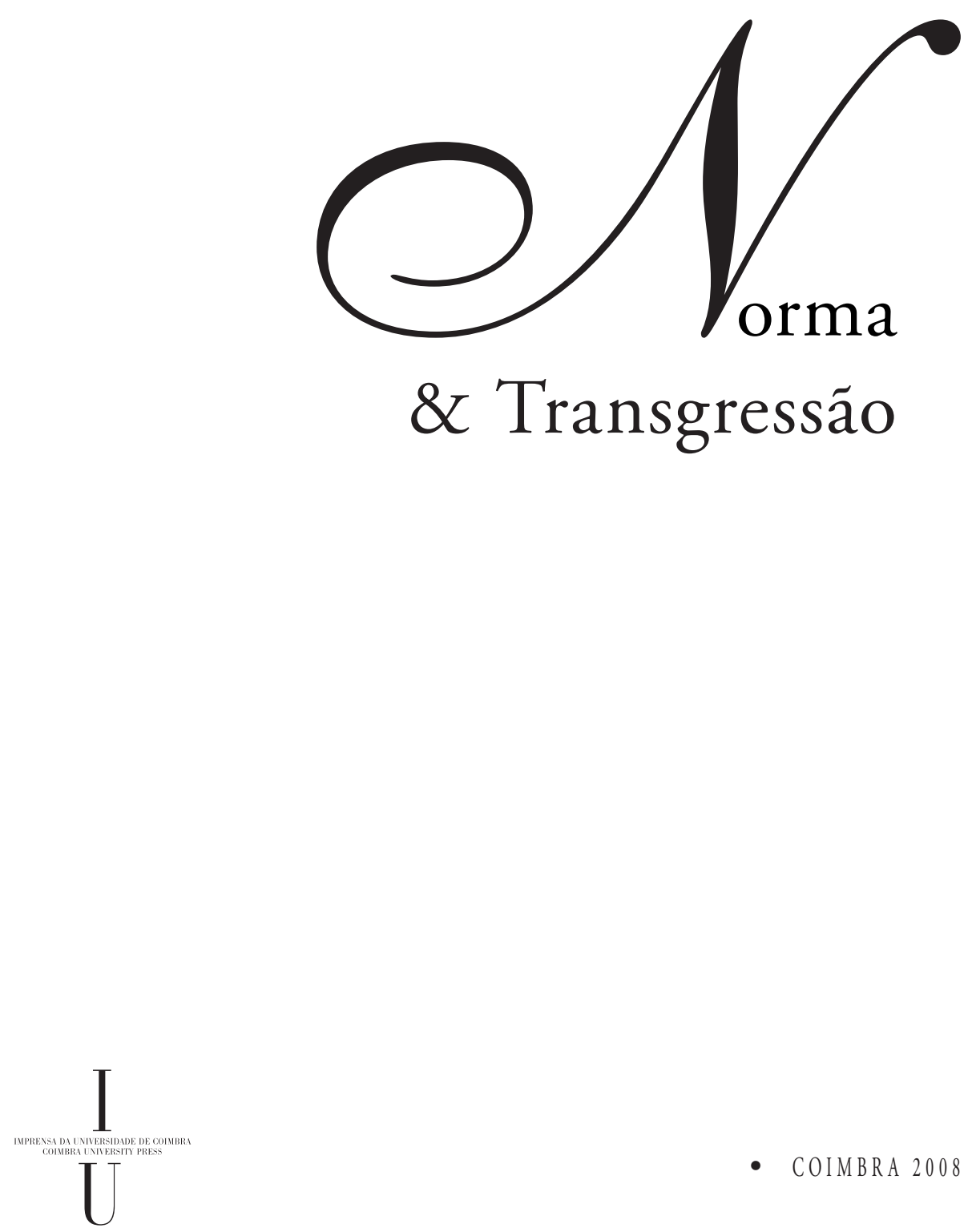

- colmbra 2008 
(Página deixada propositadamente em branco) 


\section{iiiiiiiiii

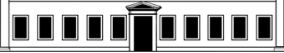

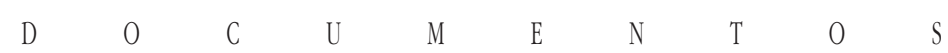<smiles>C[C@H]1OCC1(C)C</smiles> 


\title{
COORDENAÇÃO EDITORIAL \\ Imprensa da Universidade de Coimbra \\ Email: imprensauc@ci.uc.pt \\ URL: http://www.uc.pt/imprensa_uc
}

\section{CONCEPÇÃO GRÁFICA}

António Barros

Pré-IMPRESSÃo

António Resende

Imprensa da Universidade de Coimbra

\author{
EXECUÇÃO GRÁFICA \\ SerSilito • Maia
}

ISBN

978-989-8074-24-9

Depósito Legal

OBRA PUBlicada COM O APOIO de:

Centro de Estudos Clássicos e Humanísticos

Faculdade de Letras da Universidade de Coimbra

FCT Fundação para a Ciência e a Tecnologia

MINISTÉrio DA CIÊNCIA, TECNOLOGIA E ENSINO SUPERIOR Portugal

Programa Operacional Ciência e Inovação 2010

C FEVEREIRO 2008, IMPRENSA DA UNIVERSIDADE DE COIMBRA 


\section{Isabel Pedro}

Faculdade de Letras da Universidade de Coimbra

Centro de Estudos Sociais

CÉSAR E CATILINA: PERSONAS ClÁSSICAS DO «EU» NUMA AUTOBIOGRAFIA AMERICANA DO SÉCULO XX

- O CASO DE MEMoRIES OF a CATHOLIC GIRLHOOD, DE MARY MCCARTHY

\section{Resumo}

Memories of a Catholic Girlhood (1957), de Mary McCarthy, é uma autobiografia que se configura num espaço situado entre a norma autobiográfica da verdade e a transgressão subjectiva - e confessada - da ficção. O que a autobiógrafa, explicitamente preocupada com «other people's expectations of me», oferece aos leitores é, aparentemente, a autobiografia que eles querem ler, um texto que diga a verdade sobre Mary McCarthy. No entanto, são claros os sinais de aviso de que a «verdade» do texto é feita de dúvidas, simulacros, máscaras e outras verdades. Texto cuja génese e cuja forma apontam na direcção da imperfeição, as memórias de Mary McCarthy inscrevem a fragmentação e a inconsistência do "eu» numa lógica em que a incompletude da memória se transforma no factor criativo que permite, que exige mesmo, a presença transgressora da ficção.

Esta comunicação centrar-se-á em especial num capítulo, «The Figures in the Clock", em que a personagem utiliza o motivo de uma peça teatral representada na escola e o seu entusiástico desempenho do papel de Catilina para experimentar a simbologia e as possibilidades autobiográficas desta figura como alter-ego representativo do seu desejo adolescente de transgressão, confrontando-se em simultâneo com a descoberta subjectiva de "'another' 
me behind the Catilinarian poses», que é representada pela figura de Júlio César, sugestiva de uma maturidade que o eu autobiográfico resiste a reconhecer em si mesmo.

Perante a proposta de articular a questão ampla da "NORMA E TRANSGRESSÃO» com a temática da construção da identidade/alteridade, não pude deixar de pensar imediatamente, de entre todos os textos autobiográficos que conheço, em Memories of a Catholic Girlhood, ${ }^{1}$ da autora americana Mary McCarthy (1912-1989), publicado na sua forma definitiva em $1957 .{ }^{2}$

Pensei depois, em alternativa, em optar por escritas mais recentes, articulando a problemática das normas e das trangressões por entre outras fronteiras e outros percursos. Voltei, no entanto, à escolha «instintiva» de Mary McCarthy ao lembrar que um dos capítulos desta sua autobiografia, o sexto, intitulado "The Figures in the Clock", coloca exactamente a questão em análise, através da escolha de duas personagens da Antiguidade Clássica, Gaio Júlio César e Lúcio Sérgio Catilina, como representações de dois desejos opostos do «eu» adolescente que o capítulo pretende retratar.

Delineando claudicantemente os percursos da construção de uma identidade que é feita de alteridades, o tema central desta autobiografia é exactamente o da transgressão das normas, numa experimentação/interrogação das possibilidades e dos limites da criação de uma identidade subjectiva. Essa identidade constrói-se numa permanente tensão entre as definições impostas pelos outros, pelo social, pelo Outro colectivo, e o questionamento individual dessas definições, que passa necessariamente pela des-mitificação do próprio conceito tradicionalmente central numa autobiografia - o do "self», a identidade subjectiva que nos define como indivíduos únicos, isto é, diferentes - e mesmo, segundo algumas conceptualizações de inspiração romântico-liberal, independentes de ou opostos ao outro.

\footnotetext{
${ }^{1}$ (Memórias de juventude de uma menina católica). As citações deste texto serão feitas no original, seguidas da referência de página e traduzidas em nota de rodapé.

${ }^{2}$ Mary McCarthy, Memories of a Catholic Girlbood. London: Penguin Books, 1983 [1957] (as citações referem-se a esta edição). A autora produziu ainda outros dois volumes autobiográficos: How I Grew (San Diego: Harcourt Brace Jovanovich, 1987) e Intellectual Memories: New York 1936-1938 (New York: Harcourt Brace Jovanovich, 1992), publicado postumamente.
} 
No seu questionamento autobiográfico do estatuto ontológico e epistemológico do «eu» como sujeito, Mary McCarthy não se limita a uma posição de tipo kantiano segundo a qual não valeria a pena buscá-lo, pois a busca é feita pelo próprio eu, sendo então que o que se procura é já, à partida, pressuposto. Mais do que a mera preocupação com a impossibilidade subjectiva de conhecer um "eu» que seria objecto de si mesmo, a autora declara que esse objecto não existe fora do acto da procura - neste caso, do acto da linguagem. É nesse mesmo acto que o eu é criado. Segundo afirma numa entrevista posterior à publicação deste volume das suas memórias: «It's absolutely useless to look for it [the self], you won't find it, but it's possible in some sense to make it». ${ }^{3}$ Essa necessidade de "compor» o «eu», motivada pela própria experiência alienada da subjectividade (que vivemos como vacilante e instável) e pelo inerente temor de fragmentação - gémeo da consciência da nossa mortalidade - é uma das justificações implícitas para qualquer prática autobiográfica, incluindo a de Mary McCarthy.

Apesar de reconhecer a inutilidade da procura do «eu», entendido como uma entidade una, estável e auto-cognoscível que precederia a narrativa autobiográfica e que esta teria a capacidade de retratar - lembremos que nas palavras oitocentistas de Rousseau, a (sua) autobiografia é um retrato "peint exactement d'aprés nature et dans toute sa vérité» ${ }^{4}$ - Mary McCarthy baseia contudo os seus textos autobiográficos numa explícita "preocupação" de fazer coincidir a suposta posterioridade do texto com a anterioridade da vida e do sujeito e estrutura o seu discurso na base de um "pacto de referencialidade» e de um "contrato de leitura", segundo o qual o leitor pode esperar da autobiografia a verdade, e entendê-la como um retrato capaz de copiar o sujeito de modo fiel e, paradoxalmente, objectivo.

\footnotetext{
3 (É absolutamente inútil procurar o «self», pois não conseguiremos encontrá-lo; mas é possível, em certo sentido, compô-lo). Cf. The Art of Fiction, 27 (Winter-Spring 1962) 93-94.

${ }^{4}$ (pintado exactamente de acordo com a natureza e com toda a sua verdade). Jean-Jacques Rousseau, Les Confessions, [1782] s.l. Librairie Générale Française, 1963, vol. 1, 21.
} 
De facto, a autora afirma seguir - sobretudo desejar seguir - a norma autobiográfica, ou seja: contar a verdade, dizer quem foi e quem é. No texto introdutório a Memories of a Catholic Girlbood, um prefácio intitulado "To the Reader», Mary McCarthy inicia do seguinte modo a sua autobiografia:

These memories of mine have been collected slowly, over a period of years. Some readers, finding them in magazines, have taken them for stories. The assumption that I have made them up is surprisingly prevalent, even among people who know me. (9)

Desde estas primeiras palavras, o leitor é colocado perante dois níveis de descontinuidade que o texto articula. O primeiro tem a ver com a génese desta autobiografia, ou seja, o facto de os oito capítulos que a integram, escritos em épocas diferentes, terem sido publicados separadamente, entre 1944 e 1955, em diversas revistas e posteriormente coligidos e comentados pela autora, em 1957, sob a forma de Memories of a Catholic Girlhood, estabelecendo assim diferentes tempos e funções do «eu» autobiográfico. Deste modo, temos um conjunto de oito textos (os capítulos previamente publicados, que podem ser lidos independentemente como oito histórias e cuja sequência formal nem sempre corresponde a uma evolução cronológica factualmente precisa, como é o caso dos capítulos seis e sete), seguidos, todos eles, à excepção do último, "Ask Me No Questions», de posfácios, notas finais explicitamente dirigidas aos leitores, tal como o prefácio, "To the Reader", escritos para efeito da compilação e publicação conjunta dos textos iniciais. Este segundo conjunto de textos, impresso num formato tipográfico diferente, funciona como articulação, comentário, revisão crítica e "correcção" das partes que formam o primeiro texto.

Neste caso, em que o texto autobiográfico inclui a sua própria revisão, sem que, de um modo geral, as versões revistas sejam substituídas, sendo

\footnotetext{
5 (Estas minhas memórias foram sendo coligidas lentamente, ao longo de alguns anos. Alguns leitores, ao encontrá-las publicadas em revistas, tomaram-nas por histórias. A suposição de que eu as inventei é surpreendentemente preponderante, mesmo por parte de pessoas que me conhecem.)
} 
antes confrontadas com outras versões que lhes são apostas, a problemática da coalescência do eu é intensificada pela presença, para além da da autora que assina o texto, da personagem e da narradora (as duas últimas já de si multiplicadas pela situação de produção e publicação individual dos textos originais em tempos diversos), por uma outra narradora, meta-narrativamente hiperconsciente, que toma a função de editora, leitora, analista e crítica dos primeiros textos.

A norma autobiográfica, que, na famosa definição de Philippe Lejeune, coincide com «le récit rétrospectif en prose que quelqu'un fait de sa propre existence, quand il met l'accent principal sur sa vie individuelle, en particulier, sur l'histoire de sa personnalité» ${ }^{6}$, integra também um "pacto de veracidade» segundo o qual, e de acordo com o mesmo autor, o autobiógrafo se compromete, implícita ou explicitamente, a contar a verdade, estabelecendo um modo de leitura baseado em expectativas de referencialidade. Em Mary McCarthy, que afirma basear o seu texto nessas mesmas expectativas e convenções, a multiplicação, a fragmentação e a inconsistência do «eu» são integradas na própria estrutura da autobiografia e os sinais de alteridade são deliberadamente evidenciados a todos os níveis do texto.

Para além da estrutura híbrida que resulta da presença simultânea de, pelo menos, dois tipos de textos, correspondendo a vários momentos temporais de escrita, o segundo nível de descontinuidade desta autobiografia prende-se com a quase imediata "confissão» da presença de ficção nas memórias de Mary McCarthy.

Se o primeiro parágrafo de "To the Reader» estabelece à partida uma clara e categórica oposição entre memories e stories que é mais adiante repetida, agora através dos termos truth e untrue, os três parágrafos seguintes constroem uma progressiva admissão da impossibilidade prática dessa distinção, justificativamente formulada sobretudo em termos das contingências

\footnotetext{
${ }^{6}$ (o relato retrospectivo em prosa que alguém faz da sua própria existência, quando a tónica é posta na sua vida individual, particularmente na história da sua individualidade). Phillipe Lejeune, Le pacte autobiographique, Paris: Éditions du Seuil, 1975, 14.
} 
e da falibilidade da memória - ou seja: a autora admite a sua própria transgressão, confessando-a e justificando-se.

Alguns exemplos iniciais dessa admissão são invocados a partir de uma lógica que é dada como perfeitamente aceitável para o leitor mais ortodoxamente exigente: "My memory is good, but obviously I cannot recall whole passages of dialogue that took place ages ago» (9). ${ }^{7}$ O leitor fica, desde logo, informado da "honestidade narrativa» da autobiógrafa: "Quotation marks indicate that a conversation to this general effect took place, but I do not vouch for the exact words or the exact order of the speeches» (9). ${ }^{8}$ Fica também assim o leitor preparado para absolver a autora da assumida ficcionalidade dos seus diálogos: "The conversations, as given, are mostly fictional» (9).9 Mais adiante, já no posfácio relativo ao segundo capítulo, "A Tin Butterfly", depois de corrigir alguns aspectos de pormenor relativos a informações dadas no texto (utilizando expressões como "a small correction, however, is necessary» ${ }^{10}$ ) a segunda narradora acaba por pôr em questão a veracidade daquilo que é o facto central do episódio: "About the tin butterfly episode, I must make a more serious correction or at least express a doubt. An awful suspicion occurred to me as I was reading it over the other day» (73). ${ }^{11}$ Depois de explicar as suas próprias dúvidas e a forma como tentou - sem resultados concludentes - resolvê-las, recorrendo a outros testemunhos, a narradora afirma: "The most likely thing, I fear, is that I have fused two memories. Mea culpa "(73). ${ }^{12}$ A utilização da fórmula da contrição é um evidente sinal da estratégia autobiográfica confessional

7 (9) Eu tenho boa memória, mas é óbvio que não me posso lembrar de passos inteiros de diálogos que ocorreram há já imenso tempo.

${ }^{8}$ As aspas indicam que houve uma conversa sobre este assunto, mas não afianço que tenham sido usadas exactamente estas palavras nem que esta seja a ordem exacta das várias falas.

9 (As conversas, tal como as apresento, são maioritariamente ficcionais)

10 (torna-se, contudo, necessária uma pequena correcção)

11 (Sobre o episódio da borboleta de lata, tenho que fazer uma correcção mais importante ou, pelo menos, exprimir as minhas dúvidas. Ocorreu-me uma dúvida terrível quando o estava a ler no outro dia)

12 (Penso que o mais provável é eu ter misturado duas recordações. Mea culpa) 
utilizada por Mary McCarthy: o segundo texto oferece-se, à primeira vista, como uma confissão (arrependida) da existência da ficção no primeiro.

"There are several dubious points in this memoir» $(44)^{13}$ são as primeiras palavras do posfácio relativo ao primeiro capítulo, enquanto que o terceiro posfácio se inicia com a afirmação "This account is highly fictionalized» (85). ${ }^{14}$

A problemática da memória (e a sua repressão, sobretudo tratada no último capítulo, "Ask Me No Questions») é efectivamente uma questão autobiográfica central para Mary McCarthy. Em «To the Reader» a memória constitui-se complexamente como um impedimento e um incentivo à escrita autobiográfica, motivando a re-constituição da verdade do passado - e, paralelamente, da verdade do eu - e justificando a, nesta lógica, necessária presença da ficção. Orfã desde os seis anos de idade, Mary McCarthy estabelece a ficção como uma função dessa sua condição de carência, ou seja, como sinal inevitável da descontinuidade entre o seu passado, o seu presente e a memória daquele a partir deste. A perda dos pais, enquanto quebra da corrente da memória colectiva da família, é transformada na perda de uma autoridade que poderia regular a sua memória individual. A ausência dessa autoridade constitui-se num elemento criativo que possibilita duplamente a autobiografia, justificando a necessidade de recriação do sujeito e permitindo, ou mesmo gerando, a dinâmica "transgressora" do jogo verdade-ficção que mantém o «eu» em permanente «manque à être», usando múltiplas máscaras, habitando múltiplas personagens e desempenhando múltiplas funções. Re-criando-se, a autobiógrafa substitui os pais e, mais explicitamente, toma para si mesma a função reguladora da sua própria memória.

É assim justificada, a um primeiro nível, a fragmentaridade das memórias de Mary McCarthy, tanto no sentido literal da capacidade de "lembrar", como, obviamente, em termos da estrutura da narrativa autobiográfica, composta

\footnotetext{
13 (Existem alguns aspectos dúbios nesta memória)

${ }^{14}$ (Este relato é altamente ficcionalizado)
} 
por vários tipos de "fragmentos» textuais memorialistas. A busca do passado surge, deste modo, como tentativa de recuperação de uma (mítica) plenitude perdida, sendo significada (como em Freud) em termos de um exercício arqueológico, a reconstituição histórica de um passado distante apenas parcialmente acessível ou subentendido na descontinuidade dos seus vestígios fragmentados.

Mary McCarthy convoca constantemente as normas do género autobiográfico para as transgredir, mas utiliza-as explicita e estrategicamente, enquanto expectativas de leitura, como ponto de partida teórico, supostamente identificável com o seu desejo autobiográfico de ser capaz de recuperar - ou dizer - a verdade (que adjectiva de "histórica») para, na prática, demonstrar a impossibilidade de o fazer:

(. . .) to me, this record lays a claim to being historical - that is, much of it can be checked. If there is more fiction in it than I know, I should like to be set right; in some instances, which I shall call attention to later, my memory has already been corrected. $(10)^{15}$

Como já foi referido, todos os capítulos, à excepção do último, são «revistos»e, aparentemente, corrigidos. Esse último capítulo, um dos mais fragmentados em termos de estrutura narrativa e, juntamente com o prefácio, "To the Reader», um dos textos a inclui memórias da infância mais remota, centra-se na personagem da avó materna, caracterizada como "misteriosa" e sem a qual "the story would not be complete»(164). ${ }^{16}$ A ausência de texto de revisão relativo a este capítulo poderia indicar que, no final desta última história, a autobiografia fica completa. No entanto, o próprio título escolhido para o último capítulo, "Ask Me No Questions», na ressonância implicada da sua própria incompletude - trata-se de uma expressão que normalmente

15 (para mim, este registo assume-se como sendo histórico - ou seja, pode, na sua maior parte, ser verificado. Se nele existir mais ficção do que aquela de que tenho conhecimento, gostaria de ser esclarecida; em alguns casos, para os quais chamarei a atenção adiante, a minha memória já foi corrigida)

16 (a história não ficaria completa) 
é completada com as palavras "...and I'll tell you no lies»" ${ }^{17}$ - sugere exactamente o oposto: a autobiografia nunca será perfeita e o primeiro texto tem a última palavra, implícita, que parece ser a conclusão de que o «expurgar» da ficção é uma tarefa autobiograficamente impossível.

Existem ainda, entre outros mais, dois elementos que se conjugam para subverter a inicial oposição linear "memories/stories» e simultaneamente explicar - isto é, admitir e «desculpar» - a presença quase ubíqua de ficção nesta autobiografia. Esses elementos têm a ver com a auto-caracterização da personagem e da narradora/autora como, respectivamente, uma criança mentirosa e uma escritora profissional, autora de obras de ficção. Ironicamente, a ficção funciona como um parâmetro identitário, constituindo-se num facto autobiográfico central em Memories of a Catholic Girlbood: a autobiografia de uma menina mentirosa, escrita por uma autora de ficção. Ao comentar, por exemplo, um aspecto do capítulo "The Figures in the Clock», que analisaremos em mais pormenor, a narradora assume e justifica a ficcionalização como um hábito profissional:

This is a good example of 'story-telling'; I arranged actual events so as to make 'a good story' out of them. It is hard to overcome this temptation if you are in the habit of writing fiction; one does it almost automatically. $(141)^{18}$

Um dos episódios que ilustram a tendência mendaciosa e a hábil capacidade de simulação da personagem é, logo no prefácio da autobiografia, aquele que narra o caso da Primeira Comunhão, que constitui, nas palavras da narradora "one of the great moral crisis of my life» (21). ${ }^{19}$ Depois de assegurar o leitor da genuína intensidade da sua fé e da consequente - e simbólica - ansiedade relativa à primeira confissão, a narradora conta que,

\footnotetext{
17 (se não me fizerem perguntas eu não minto)

${ }^{18}$ (Trata-se de um bom exemplo de "contar histórias»; compus os acontecimentos reais de modo a transformá-los numa "boa história". É difícil não se ceder a essa tentação quando se tem o hábito de escrever ficção - é algo que se faz quase automaticamente)

19 (uma das grandes crises morais da minha vida)
} 
por distracção, bebeu um gole de água antes da comunhão, quebrando assim o preceito de jejum e podendo incorrer em pecado mortal caso decidisse comungar nessas condições. Descreve-se então o conflito entre a consciência subjectiva da transgressão e o "dever social» - aliado ao desejo pessoal - de satisfazer as expectativas dos outros: "I could not take Communion. And yet I had to» (21). ${ }^{20}$ Se confessasse o que fizera, como era sua obrigação moral, teria que desistir da cerimónia, alterando todos os planos e expectativas dos colegas, da escola, da família (e também os seus...). Perante este dilema, apesar de saber que, se comungasse em estado de pecado mortal, "God would never forgive me; it would be a fatal beginning" (21), ${ }^{21}$ Mary acaba por sucumbir à tentação sacrílega e recebe o sacramento «in a state of outward holiness and inward horror» (21). ${ }^{22}$

Para além da irónica revelação deste primeiro acto público de fé como uma farsa (justificada pelo conflito de deveres), esta descontinuidade dos seus «eus», o interior, a verdade que ninguém para além dela conhece, e o exterior, a imagem fabricada para satisfação "pública», torna-se num paradigma que a narradora generaliza nos seguintes termos:

Every subsequent moral crisis of my life, moreover, has had precisely the pattern of this struggle over the first Communion; I have battled, usually without avail, against a temptation to do something which only I knew was bad, being swept on by a need to preserve outward appearances and to live up to othet people's expectations of me. (22, sublinhados meus $)^{23}$

São exemplos deste padrão, entre outros, o episódio da perda de fé (outro elemento de descontinuidade na autobiografia de uma infância

\footnotetext{
${ }^{20}$ (Eu não podia comungar. E, no entanto, tinha que o fazer)

21 (Deus nunca iria perdoar-me; seria um começo fatal)

22 (num estado de santidade exterior e de horror interior)

23 (Todas as crises morais que se sucederam na minha vida tiveram precisamente o mesmo padrão desta luta relativa à Primeira Comunhão; lutei, normalmente sem resultado, contra a tentação de fazer algo que só eu sabia ser mau, sendo impelida por uma necessidade de preservar as aparências exteriores e de satisfazer as expectativas que as outras pessoas tinham relativamente a mim)
} 
católica e outro elemento de subversão do padrão clássico da autobiografia: tradicionalmente uma história de "conversão», como em Santo Agostinho) e outros que marcam importantes etapas de crescimento: a suposta menarca, a formatura e a primeira experiência sexual. Em todos eles, de uma forma geral, Mary joga com as expectativas dos outros - que dão um lugar ao "eu» no social, satisfazendo o seu desejo de pertença - em tensão com o desejo individual de ser diferente. Em todos eles, a imagem exterior de si que Mary falsifica parece corresponder a uma exigência social que supostamente a obriga a fingir o que não é, uma mera efígie de si própria construída para satisfazer os outros e, assim, de forma quase maquiavélica, obter o seu reconhecimento, a sua aceitação e a validação de si própria como sujeito..

No colégio de freiras católicas que frequentava aos doze anos, afirma a narradora: "it was the idea of being noticed that consumed all my attention»(94); ${ }^{24}$ mais adiante, decide: "I was going to get myself recognized at whatever price» (96), ${ }^{25}$ concluindo, amoral e determinada: «If I could not win fame by goodness, I was ready to do it by badness" (96). ${ }^{26}$ Referindo a ocasião em que decide mentir deliberada e elaboradamente durante uma confissão, a narradora usa termos que constituem outras tantas referências de ficcionalização: "não eu», "efígie», "fraude», "simular», "fingir», "representar"...

É ainda no posfácio que complementa este capítulo, "C’Est Le Premier Pas Qui Coûte», que a narradora afirma "My chief interest was the stage; the wish to play a part, and attract notice, together with a quick memory, had persuaded me that I was born for the footlights» (109). ${ }^{27}$

\footnotetext{
${ }^{24}$ (era a ideia de ser notada que consumia toda a minha atenção)

25 (eu iria conseguir que me reconhecessem fosse qual fosse o preço a pagar)

26 (Se não conseguisse obter fama pela bondade, estava pronta a consegui-lo pela maldade)

${ }^{27}$ (O meu interesse principal era o palco; o desejo de desempenhar um papel e de chamar a atenção, em conjunto como uma certa facilidade de memória, tinham-me convencido de que eu nascera para as luzes da ribalta)
} 


\section{"The Figures in the Clock"}

O capítulo seis, "The Figures in the Clock", inicia-se com uma explicação da narradora, que diz ter encontrado, ao folhear uma antiga gramática de Latim para ajudar o filho nos trabalhos da escola, um relativamente longo rol de "compras" escrito com a sua letra e que identifica como sendo uma lista de materiais para a confecção do trajo de Catilina para a peça do clube de Latim da autoria da respectiva professora. A analepse que se segue conduz-nos a uma Mary de dezasseis anos, que está prestes a concluir o curso do liceu no colégio interno (Annie Wrights Seminary) que frequentava desde os treze e para onde os avós a tinham enviado supostamente em desespero de causa...

A referência "my Catiline costume for the Latin Club play, 'Marcus Tulius'» $(121)^{28}$ é revista de imediato, sendo substituída pela expressão "the matrix from which gorgeous Catiline would emerge» (121-2) ${ }^{29}$ (sublinhado meu) e seguida pela descrição exaustiva da personagem romana na primeira pessoa, criando um efeito de uma máscara que se cola ao actor que a usa:

those dish-rags, dipped in gold paint and sewn together (. . .) would be my chain-armour breast-plate; the oilcloth, gold, stiffened with cardboard and crowned with a red plume, my helmet; the flame Indianhead my military cloak, as I appeared in the fearsome scene of the Battle of Pistoria, where I rushed into the ranks of the enemy and met my death with great bravery.(122) $)^{30}$

Será de esperar a reacção de estranheza dos leitores perante o protagonismo especialmente cuidado que é dado à personagem de Catilina numa peça teatral denominada "Marcus Tulius», sendo a expectativa mais imediata que

\footnotetext{
28 (o meu guarda-roupa de Catilina para a peça do clube de Latim, "Marco Túlio»)

29 (a matriz a partir da qual surgiria o magnífico Catilina)

30 (os panos de cozinha, tingidos de dourado e cosidos uns aos outros seriam a minha couraça de cota de malha; o oleado, também dourado, reforçado com cartão e encimado por uma pluma vermelha, o meu capacete; as penas de índio cor de fogo seriam a minha capa militar quando aparecesse na cena terrível da batalha de Pistóia, onde, arremetendo contra as fileiras do inimigo com grande bravura, eu encontraria a minha morte)
} 
Catilina fosse tratado como vilão. Porém, a narradora continua a referir Catilina na primeira pessoa, a voz de Mary narrando a acção dramática da sua personagem (que o texto claramente já estabeleceu como sua persona) num registo autobiográfico e em termos surpreendentemente aclamatórios, enquanto as outras personagens são relegadas para um plano secundário e descritas de forma pouco dignificante como "foppish Caesar and sallow Cato». (123) 31

O desempenho de Catilina por parte de Mary transforma-o num herói romântico: belo, solitário, renegado, admirável mesmo quando - ou possivelmente exactamente porque - acusado de «adulterer, extortioner, profligate, bankrupt, assassin, suspected wife-killer, broken-down patrician, demagogue, thug" (123-4). ${ }^{32}$ As acusações de Cicero, obviamente coincidentes com características de um intolerável comportamento anti-social, funcionam como um apelo à identificação da adolescente que busca a sua afirmação pela diferença rebelde e pela negação dos valores estabelecidos, de tal forma que Mary chega a afirmar, explicitando o sentido dos sinais nomeadamente o jogo de pronomes pessoais e possessivos - que abundam nesta parte do texto: "To my mind, Catiline was not only a hero - he was me» (124). ${ }^{33}$ Mary confessa-se determinada a «inverter o veredicto da história», afirmando que "the vindication of Catiline appeared to me a task of consumate importance» (125).34

Reservado para a apresentação pública da peça um desempenho excessivo, triunfante e sedutor que não era previsto no texto dramático da professora nem fora preparado nos ensaios, as capacidades de representação da jovem Mary conseguem efectivamente angariar a adesão do público (e principalmente a das colegas do oitavo ano) para a sua personagem, concretizada no facto de que, segundo a narradora, "Catiline's applause swelled above Cicero's" (126). ${ }^{35}$

\footnotetext{
31 (o enfatuado do César e o macilento do Catão)

32 (adúltero, extorcionista, devasso, libertino, falido, assassino, suspeito de uxoricídio, patrício arruinado, demagogo, bandido)

33 (Na minha ideia, Catilina não era apenas um herói - era eu própria)

34 (vingar Catilina parecia-me ser uma tarefa da maior importância)

35 (O aplauso a Catilina superou o de Cícero)
} 
Esta perturbante demonstração de capacidade de manipulação do público (pelo menos de uma parte - ruidosa... - do público) parece, mais uma vez, apontar para a artificialidade ficcional da representação do eu autobiográfico, num «mise-en-scène» elaborado capaz (ou não...) de dirigir as simpatias dos leitores em sentidos que poderão inverter "o veredicto da história»...

No entanto, a história das simpatias clássicas de Mary não se conta de forma tão simples. No preciso momento em que defende denodadamente a "sua» personagem, proferindo o discurso relatado por Salústio, Mary confessa que «this speech, from the start, had bothered me. With its threats and bombast, its Senecan frigidity, it sounded guilty and rather stupid» (124) ${ }^{36}$ e diz ainda que, apesar de ter em conta o preconceito de Salústio contra Catilina e a tradução formal e rígida de Miss Gowrie, a professora de Latim, o efeito de repetição dos ensaios tinha dado origem a uma pequenina dúvida na sua mente: "Was the Catiline I admired so much merely a vulgar arsonist, as Cicero and his devotees contended?» (124) ${ }^{37}$ A dúvida confessada é, contudo, rejeitada logo de seguida: "These first stirrings of maturity were very unwelcome» (124). ${ }^{38}$ Vista à distância da narradora presente, a MaryCatilina não se conhece a si mesma: "It did not, of course, occur to me that there was also 'another' me behind the Catilinarian poses» (132). 39 É o eu "maduro" que convive com o eu adolescente e que este rejeita, o eu que se apaixona, ao estudar os Comentários sobre as guerras da Gália, pela figura «just, lacolic, severe, magnanimous, detached» (132). ${ }^{40}$

O eu de Mary é um eu dividido, no qual se cruzam desejos e lealdades antagónicas - o desejo rebelde da diferença e da trangressão debatendo-se

\footnotetext{
${ }^{36}$ (o discurso tinha-me causado problemas desde o início. Com as ameaças e o estilo bombástico, e a frigidez tipo Séneca, parecia estúpido e culpado)

37 (Será que o Catilina que eu tanto admirava não passava de um pirómano ordinário, como afirmavam Cícero e os seus seguidores?)

38 (Estes primeiros sinais de maturidade eram muito inoportunos)

39 (É claro que não me occorreu que havia um 'outro' eu por detrás das poses de Catilina)

${ }^{40}$ (justa, lacónica, severa, magnânime, independente, de Júlio César)
} 
com a normalidade social, a aceitação da ordem e da lei. A metáfora bélica dá-nos conta dessa simultaneidade:

Justice, goodwill, moderation, and uncommon fidelity - why should these substantives of virtue have stirred the Seminary's Catiline? At the time, I was sublimely unaware that my fortifications had been breached, that the forces of law and order were pacifying the city while the rebel standard still waved on the ramparts. $(136)^{41}$

Júlio César representa, neste capítulo da autobiografia, o oposto de Catilina, as forças contidas da lei e da ordem, da objectividade imparcial. Não é por acaso que, para além das qualidades invocadas, a paixão de Mary por esta personalidade é declaradamente motivada pela admiração das suas qualidades de escritor. De «temperamento objectivo» e "espírito de justiça», o cronista de guerra, o autobiógrafo dos seus feitos militares é «the bald instrument of empire who wrote not 'I' but 'Caesar'» (132)42, (é também um geógrafo curioso e, curiosamente, um romano com a adaptabilidade que o torna capaz de dar a volta ao inimigo através de um estudo das suas próprias técnicas). Ou seja, César possui imparcialidade e objectividade, as características que, em "To the Reader» a autobiógrafa declara pretender praticar - para rapidamente confessar a sua impossibilidade.

No entanto, as identificações de Mary não se ficam ainda por aqui. Antes do final do capítulo, ambas são postas em causa. Distanciada do seu «eu» narrado, a narradora afirma saber agora que o seu alter-ego representativo de «my childish rebeliousness and demagogic vanity» (138), ${ }^{43}$ do seu suposto dever de «break the rules and take all offered risks»(138), ${ }^{44}$ era "a murderer,

\footnotetext{
${ }^{41}$ (Justiça, boa-vontade, moderação e invulgar fidelidade - por que razão haveriam estes substantivos de virtude de ter mexido com a Catilina do Seminário Annie Wright? Naquela altura, eu não me tinha minimamente apercebido de que as minhas fortificações tinham sido violadas, que as forças da lei e da ordem pacificavam a cidade enquando o estandarte rebelde ainda ondulava nos baluartes)

42 (o frio instrumento do império que não escrevia "eu» e sim "César»)

43 (a minha rebeldia infantil e a vaidade demagógica)

${ }^{44}$ (transgredir e aceitar correr todos os riscos)
} 
who slew his own brother-in-law and tortured a man to death (. . .) a gangster and a ruffian» (137). ${ }^{45}$ Quanto a César, o alter-ego alternativo, não é afinal isento de culpas. Conhecida a história de Vercingetorix e de Dumnorix, que não abonam em favor da clemência do general, a narradora acrescenta ironicamente:

He shuddered and burst into tears when they brought him Pompey's head, unsolicited, and in the Gallic Wars only three atrocities, minute by modern standards, defaced his record of clemency: the flogging to death of two chiefs and the cutting off the hands of the defenders of Uxellodunum. Hail Caesar! $(137)^{46}$

Como personagem histórica, César não é uma figura unívoca nem monolítica. Celebrado por muitos, detraído por muitos outros, nunca será possível conhecer quem foi Gaio Júlio César. Quanto a Catilina, até Salústio, que tão minuciosamente lhe retratou os vícios, lhe reconheceu qualidades nobres e de grande valor para os romanos.

No final do capítulo, parecem então cair por terra as oposições simplistas que foram experimentadas como ilustração do tema que a autobiógrafa explicitamente propõe: «juvenile delinquency versus maturity» $(142)^{47}$, parecendo agora questionar-se a adequação absoluta de qualquer dos dois modelos.

"The Figures in the Clock», contudo, é seguido por um posfácio em que Mary McCarthy volta a vestir, indirectamente, a pele dos dois romanos ao identificá-los com membros da sua família, Júlio César com o avô materno, o advogado que ela considera um homem «justo, lacónico, severo, magnânimo, independente» e Catilina com os seus antepassados do lado paterno - "the

\footnotetext{
${ }^{45}$ (um assassino que matou o próprio cunhado e torturou um homem até à morte (. . .) um criminoso e um facínora)

46 (César estremeceu e chorou quando lhe trouxeram, sem ele o solicitar, a cabeça de Pompeu e nas guerras da Gália apenas três atrocidades, aliás mínimas pela medida actual, lhe desfeiam o registo de clemência: o flagelamento até à morte de dois chefes e o decepar das mãos dos defensores de Uxellodunum. Avé César!)

47 (Delinquência juvenil em oposição a maturidade)
} 
wild streak in my heredity, the wreckers of the Nova Scotia coast» (142). ${ }^{48}$ Perante as alternativas agora metaforizadas como herança, a narradora do segundo texto afirma-se surpreendida por ter escolhido César, a norma em vez da transgressão, embora, de novo contrariando uma resolução simples da oposição, acrescente que "This does not mean that the see-saw between these two opposed forces terminated" (142). ${ }^{49}$ Efectivamente, a autobiógrafa confirma finalmente que as duas vertentes, o desejo de transgressão e o respeito pela norma integram a história do seu percurso identitário, uma história que se inscreve numa privação inicial que é partilhada com os irmãos, ou seja a situação de orfandade, que, como vimos, é uma das motivações para a procura autobiográfica do «eu»: «The injustices my brothers and I had suffered in our childhood had made me a rebel against authority but they had also prepared me to fall in love with justice, the first time I encountered it» (142). ${ }^{50}$

\section{Bibliografia/obras citadas}

"Interview», The Art of Fiction, 27 (Winter-Spring 1962), 93-94

Lejeune, Phillipe, Le pacte autobiographique, Paris: Éditions du Seuil, 1975, 14

McCarthy, Mary, Memories of a Catholic Girlhood. London: Penguin Books, 1983

Rousseau, Jean-Jacques, Les Confessions, s.l.: Librairie Générale Française, 1963, vol. 1, 21

\footnotetext{
48 (o elemento temerário da minha hereditariedade, os piratas das costas da Nova Escócia)

49 (Isto não significa que o vai-vem entre estas duas forças tivesse terminado)

50 (As injustiças que os meus irmãos e eu sofremos na nossa infância tinham-me tornado numa rebelde contra a autoridade, mas também me prepararam para me apaixonar pela justiça da primeira vez que com ela me deparei)
} 


\section{Série}

\section{Documentos}

Imprensa da Universidade de Coimbra

Coimbra University Press

2008

- $\mathrm{U}$

C • 